\title{
Teaching Individuals with Autism Problem-Solving Skills for Resolving Social Conflicts
}

\author{
Victoria D. Suarez ${ }^{1} \cdot$ Adel C. Najdowski $^{2}$ (D) Jonathan Tarbox ${ }^{3} \cdot$ Emma Moon $^{2,4} \cdot$ Megan St. Clair ${ }^{4} \cdot$ Peter Farag $^{4}$
}

Accepted: 5 August 2021 / Published online: 30 August 2021

(C) Association for Behavior Analysis International 2021

\begin{abstract}
Resolving social conflicts is a complex skill that involves consideration of the group when selecting conflict solutions. Individuals with autism spectrum disorder (ASD) often have difficulty resolving social conflicts, yet this skill is important for successful social interaction, maintenance of relationships, and functional integration into society. This study used a nonconcurrent multiple baseline across participants design to assess the efficacy of a problem-solving training and generalization of problem solving to naturally occurring untrained social conflicts. Three male participants with ASD were taught to use a worksheet as a problem-solving tool using multiple exemplar training, error correction, rules, and reinforcement. The results showed that using the worksheet was successful in bringing about a solution to social conflicts occurring in the natural environment. In addition, the results showed that participants resolved untrained social conflicts in the absence of the worksheet during natural environment probe sessions.
\end{abstract}

Keywords Autism $\cdot$ Executive function $\cdot$ Perspective taking $\cdot$ Problem solving $\cdot$ Social conflict

Problem solving is traditionally defined as the ability to identify the problem and then create solutions for the problem (Agran et al., 2002). From a behavioral perspective, a person is faced with a problem when they experience a state of deprivation or aversive stimulation (Skinner, 1953, p. 246), and reinforcement is contingent upon a response that is in the person's repertoire, but cannot be evoked under current conditions (Palmer, 1991, 2009). According to Skinner (1953), "problem-solving may be defined as any behavior which, through the manipulation of variables, makes the appearance of a solution more probable" (p. 247). Therefore, problem solving involves mediating or precurrent behaviors that function to manipulate or generate discriminative stimuli needed to evoke a resolution response (Palmer, 1991; Skinner, 1984).

Adel C. Najdowski

adel.najdowski@pepperdine.edu

1 Endicott College, Beverly, MA, USA

2 Pepperdine University, Malibu, CA, USA

3 University of Southern California, Los Angeles, CA, USA

4 Halo Behavioral Health, Valley Village, California, USA
See Szabo (2020) for a conceptual analysis of problem solving.

Behavioral researchers have taught specific problemsolving strategies to individuals for learning specific skills (see Axe et al., 2019 for a review), such as categorizing items (Kisamore et al., 2011; Sautter et al., 2011), explaining how to complete tasks (Frampton \& Shillingsburg, 2018), and completing vocational tasks (Lora et al., 2019). Such problemsolving strategies functioned to teach participants to engage in mediating or precurrent behaviors that brought about a resolution. For example, Sautter et al. (2011) taught participants to use rules as a precurrent behavior to evoke the resolution of sorting stimuli. Kisamore et al. (2011) taught participants a visual imagining strategy as a precurrent behavior to evoke the resolution of categorizing. Frampton and Shillingsburg (2018) taught participants to sort and sequence visual stimuli of each step of a multistep task as a precurrent behavior to evoke explaining how to complete the multistep task.

Another type of scenario that requires one to engage in problem solving is when dealing with social conflict. Resolving social conflicts likely involves similar precurrent behaviors addressed in previous behavioral literature, such as behavior chains, rules, self-questioning, sequencing, and potentially visual imagining (See Axe et al., 2019, for a review). However, because social conflicts by definition 
involve interacting with other people, successfully resolving social conflicts also likely involves engaging in perspective taking, including tacting others' perspectives, engaging in deictic relating behavior by switching perspectives (Luciano et al., 2020), and likely arranging for others involved in the conflict to also obtain reinforcement.

According to traditional psychology, problem solving begins to develop as early as the preschool years (e.g., Best et al., 2009; Garon et al., 2008). Yet, individuals with autism spectrum disorder (ASD) often display deficits in social skills (American Psychiatric Association [APA], 2013) and have been found to demonstrate difficulties resolving social conflicts (Bernard-Optiz et al., 2001).

Given that a defining feature of ASD is to present with deficits in social communication and interaction (APA, 2013) and that resolving social conflicts across a wide range of situations is essential for functional integration into society and the maintenance of relationships (Bonete et al., 2015), it appears necessary to identify effective methods for teaching individuals with ASD to engage in problem-solving skills that will aid social conflict resolution. However, behavioral research has not evaluated methods to teach problem-solving skills in this context specifically to individuals diagnosed with ASD.

Although the population of ASD has not been studied in previous behavioral research on using problem-solving strategies to deal with social conflicts, a study conducted by Park and Gaylord-Ross (1989) used behavioral procedures to teach individuals with intellectual disabilities precurrent behaviors including rules, self-questioning, and self-prompting to solve problems they encountered at work, including social initiations, mumbling, and conversation expansions and terminations. During training, the researchers provided participants with a picture of themselves in a social situation (e.g., passing by a familiar customer at their workplace) and asked them how they would behave in the presented situation. Participants were provided with seven rules or questions to ask themselves: (1) What is happening? (2) What are three behaviors I could emit? (3) What will be the outcome of each behavior? (4) Which is better? (5) Pick one (6) Emit the behavior and (7) How did I feel? Prompting, modeling, and praise were used to teach participants to use the seven rules/ questions. Pictures of novel social situations (other than the target situation) were presented at the end of training sessions to assess generalization to untrained stimuli and only one of three participants demonstrated stimulus generalization. During follow-up, an audiocassette recorder was placed in the participants' shirt pockets to record their interactions during their work and evaluate generalization of responding to trained stimuli in the natural environment. The results of the study indicated that participants' target behaviors improved during training, and follow-up performance in the natural environment improved compared to baseline.
In addition to the paucity of research on this topic within behavior analysis, there is limited research outside of the behavioral literature that has evaluated methods for teaching individuals with ASD to use problem-solving strategies for dealing with social conflicts. One notable exception is a study conducted by Bernard-Optiz et al. (2001), who used a webbased problem-solving program to teach typically developing children and children with ASD to select and develop appropriate solutions. In particular, social conflicts were presented to participants on a computer screen with choices of possible solutions and an option to insert an individualized solution. For example, participants were shown a scenario in which two children wanted a turn to go down a slide. An audio cue asking, "What would you do?" was presented, and icons offering problem-solving solutions, such as requesting to go first, were provided. A second audio cue asking, "Do you have any good ideas?" was subsequently presented, and the option to insert a unique solution was presented. Novel solutions identified by participants resulted in social praise, and the option to continue inputting novel solutions continued to appear until participants no longer produced additional responses. All participants demonstrated an increase in the number of appropriate novel solutions generated. The results of Bernard-Optiz et al. (2001) demonstrated that social praise and a web-based problem-solving program functioned to increase generativity of problem solutions. Moreover, the results demonstrated that participants with ASD were taught to generate novel solutions to social conflicts using prompts and reinforcement. However, as the authors point out, a limited selection of social conflict scenarios were presented during intervention. Perhaps the most substantial limitation to the study is the use of an analogue computer task, without assessing whether problem-solving skills improved during real-life social interactions. In addition, maintenance was not measured.

Although behavioral research has found that teaching precurrent behaviors led participants to solve problems (e.g., Frampton \& Shillingsburg, 2018; Kisamore et al., 2011; Lora et al., 2019; Park \& Gaylord-Ross, 1989; Sautter et al., 2011), no research of which we are aware has evaluated the effects of teaching precurrent behaviors for resolving social conflicts to individuals with ASD. Further, although nonbehavioral research demonstrates prompts and social praise may function to increase resolving social conflicts in children with ASD (Bernard-Optiz et al., 2001), it is unknown if prompts and reinforcement would be successful in teaching individuals with ASD to use precurrent behaviors to resolve social conflicts. In addition, although research by Park and GaylordRoss (1989) measured generalization to trained problems in the natural environment, there is a dearth of research measuring generalization to untrained social conflicts occurring in the natural environment. Furthermore, research that has evaluated generalization to untrained problems found positive 
results with only one of three participants (Park \& GaylordRoss, 1989).

The purpose of the current study was to investigate the effects of a problem-solving training package conducted in the natural environment on the use of problem-solving skills (i.e., precurrent behaviors) to resolve untrained social conflicts by individuals with ASD. The problem-solving training package consisted of a problem-solving worksheet, multiple exemplar training, error correction, rules, and reinforcement. Generalization of problem solving to untrained conflicts was programmed for by using multiple exemplar training and was assessed throughout the course of the study.

\section{Method}

\section{Participants and Setting}

Three male individuals, with primary language being English, participated. Patrick was an 11-year-old Indigenous, Latinx, and white male with diagnoses of ASD, attention-deficit hyperactivity disorder (ADHD), and bipolar disorder. Oliver was a 22-year-old Israeli male with a diagnosis of ASD. Russell was a 10-year-old Indigenous, Latinx, and white male with diagnoses of ASD and ADHD.

All participants received applied behavior analytic (ABA) services from a community-based agency for $10-12 \mathrm{hr}$ per week. They demonstrated a listener behavior repertoire by engaging in auditory-visual conditional discriminations and following multistep instructions, used vocal-verbal communication in full sentences, and read and wrote basic paragraphs (i.e., three to five sentences). In addition, they demonstrated well-developed language skills by engaging in echoics, mands, tacts, and intraverbals. All participants labeled emotions in others (e.g., answered "How does she feel?"), identified cause-and-effect (e.g., answered "Why?" and "What will happen if . . . ?" For example, "Why did the egg break?" ["Because you dropped it."], or "What will happen if I drop this egg?" ["It will break."]), identified emotional cause-andeffect (e.g., answered "Why is she sad?" or "What will happen if someone takes her toy?"), and followed rules (e.g., "If you're wearing pink, then raise your hand."). In addition, participants used pronouns in speech and demonstrated listener behavior according to pronouns. All participants had a history of learning via role play and engaged in up to four intraverbal exchanges with others. At the time of recruitment, Patrick's overall score on the Basic Living Skills Assessment Protocol from the Assessment of Functional Living Skills (AFLS) was 469 and Russell's overall score was 475. No standardized assessment scores are available for Oliver, because his most recent assessment conducted prior to participation in this study was conducted using a commercially available webbased platform that does not provide raw scores. Participants were included because they did not independently and appropriately resolve social conflicts, and deficiency in resolving social conflicts was affecting their maintenance of positive relationships with siblings or parents. Individuals who demonstrated significant challenging behavior severe enough to interfere with instruction (e.g., self-injurious behavior [SIB], moderate to severe aggression) were ineligible to participate.

Participants were recruited because they were determined to benefit from learning to resolve social conflicts by their supervising clinician. Moreover, participants were recruited by asking them (for Oliver) or their parents (for Patrick and Russell) if they would like to participate in a research study evaluating a lesson for teaching problem-solving skills to resolve social conflicts. Consent was obtained by providing a consent form outlining the study's purpose, methods, and potential benefits/risks to Oliver and the parents of Patrick and Russell. In addition, assent forms were provided to Patrick and Russell.

Research sessions were conducted during regularly scheduled ABA-based teaching sessions in home-based and clinicbased settings for the duration of the study with the exception of Oliver who made a transition from home- and clinic-based sessions to solely telehealth sessions (due to the COVID-19 pandemic) beginning with session 21 . Research sessions were conducted in various rooms throughout the session environment (e.g., bedroom, living room, lobby, conference room). Research sessions were 5-30 min in length and consisted of the presentation of one problem. One to two research sessions (conducted at least $30 \mathrm{~min}$ apart) were conducted 1-3 days per week.

\section{Response Measurement and Data Collection}

A problem-solving task analysis (TA; Table 1) was used to calculate the percentage of correct, independent problemsolving steps completed by each participant. Each step of the TA was scored as correct or incorrect based on the specified criteria (Table 1). A correct response included independently and accurately completing a step within the task analysis by either writing a response or vocally stating a response within $10 \mathrm{~s}$ of: (1) the problem occurring (step 1) and (2) the previous step being completed (steps 2-13). An incorrect response included responses irrelevant to the current step, prompted responses, and nonresponses (i.e., failure to respond within $10 \mathrm{~s}$ of the problem [step 1] or previous step occurring [steps 214]). During baseline and posttraining, if the participant was not progressing through the conflict (e.g., not doing anything to resolve the conflict) after $1 \mathrm{~min}$ of the problem occurring, the conflict was ended by the interventionist resolving the conflict (e.g., if the conflict was that brother left Legos on the table where the participant was going to eat, the interventionist resolved the conflict by removing the Legos) and all remaining steps of the TA were scored as incorrect. 
Table 1 Problem-solving task analysis

Steps

1 Identifies the problem.

A correct response was recorded if the participant accurately identified the problem within $10 \mathrm{~s}$ of the problem occurring. An incorrect response was recorded if they were nonresponsive or stated something other than the problem.

2 Identifies own perspective of what happened.

A correct response was recorded if the participant provided a response that was contextually appropriate for the given situation within $10 \mathrm{~s}$ of completing step 1 . An incorrect response was recorded if they were nonresponsive or the response was contextually irrelevant to the participant's current experience with the problem.

3 Identifies what the other person thinks happened.

A correct response was recorded if the participant provided a response that was contextually appropriate to what the other person could have potentially experienced (even if it was not what the person actually experienced) within $10 \mathrm{~s}$ of completing step 2 . An incorrect response was recorded if they were nonresponsive or the response was contextually irrelevant to what the other person could have potentially experienced.

4 Identifies possible solution 1.

A correct response was recorded if the participant provided a solution that would be possible to carry out and was contextually relevant to the problem within $10 \mathrm{~s}$ of completing the previous step. An incorrect response was recorded if they were nonresponsive or the response was contextually irrelevant to solving the problem.

5 Identifies likely outcome of solution 1.

A correct response was recorded if the participant identified a possible outcome to the proposed solution within $10 \mathrm{~s}$ of completing the previous step. An incorrect response was recorded if they were nonresponsive or the response was contextually irrelevant to the problem's outcome or was not a possible outcome of the solution.

6 Identifies possible solution 2.

The definition of step 4 applied here.

7 Identifies likely outcome of solution 2.

The definition of step 5 applied here.

$8 \quad$ Identifies possible solution 3.

The definition of step 4 applied here.

9 Identifies the likely outcome of solution 3.

The definition of step 5 applied here.

10 Selects the best solution.

A correct response was recorded if the participant selected any one of the three solutions (steps 4, 6, and 8) that had positive likely outcomes within $10 \mathrm{~s}$ of completing step 9 . An incorrect response was recorded if they were nonresponsive; selected a solution other than those generated for steps 4,6 , and 8 ; or selected one of the three solutions that had likely negative outcomes. Likely negative outcomes were defined as those that would not fix the problem or could potentially make the situation worse.

11 Implements the selected solution.

A correct response was recorded if the participant began to carry out the solution selected in step 10 within $10 \mathrm{~s}$ of completing step 10 . An incorrect response was recorded if they were nonresponsive or engaged in any other behavior besides the solution chosen in step 10.

12 Evaluates whether the solution worked.

A correct response was recorded if the participant identified accurately by answering "yes" or "no" regarding whether their solution solved the problem within $10 \mathrm{~s}$ of completing step 11. An incorrect response was recorded if the participant was nonresponsive or if the response did not accurately indicate whether the solution worked.

13 Identifies what was learned.

A correct response was recorded if participants identified how the solution they used was related to solving the problem within $10 \mathrm{~s}$ of completing step 12. An incorrect response was recorded if the participant was nonresponsive or if the response was contextually irrelevant to how the solution used was related to the outcome achieved.

Note: Task analysis (TA) steps and correct response criteria for each TA step.

Natural environment probes (explained below) were scored as all or nothing. If the participant successfully resolved the social conflict by engaging in a viable solution (i.e., any solution that would function to resolve the conflict and could be readily carried out) within $10 \mathrm{~s}$ of the conflict occurring, the natural environment probe was scored as $100 \%$ correct. On the other hand, if the participant failed to resolve the social conflict (i.e., proposed and/or engaged in an impracticable solution or was nonresponsive as defined earlier), the natural environment probe was scored as $0 \%$ correct.

Interobserver agreement (IOA) was collected by two independent observers who recorded data during $33 \%$ of baseline sessions for all participants. IOA data were collected during $50 \%, 62 \%$, and $57 \%$ of training sessions for Patrick, Oliver, and Russell, respectively. Moreover, IOA data were collected during $67 \%$ of posttraining sessions for Patrick and Oliver and 
$50 \%$ for Russell. IOA data were collected during $75 \%$ of follow-up sessions for Patrick and $100 \%$ for Oliver and Russell. Finally, IOA data were collected during 50\%, 40\%, and $50 \%$ of natural environment probes for Patrick, Oliver, and Russell, respectively. Point-by-point agreement was used to identify observers' agreement on whether each step was performed correctly versus incorrectly by dividing the number of steps for which there was agreement by the total number of steps and multiplying the resulting quotient by $100 \%$.. Mean IOA was $100 \%, 98.8 \%$ (range; $90 \%-100 \%$ ), and $98.7 \%$ (range: 90\%-100\%) for Patrick, Oliver, and Russell, respectively.

\section{Experimental Design and Procedure}

A nonconcurrent multiple baseline across participants design was used to assess the effects of the problem-solving training package.

\section{General Procedures}

At the beginning of each ABA-based teaching session, participants were provided with a variation of the following instruction: "Today during your session, a social problem with someone will happen at some point. Here is a worksheet [see Fig. 1] you can use to help solve the problem when it happens." The worksheet was written using language that was previously observed to be used by the participants and that they were familiar with.

Then, ABA-based teaching activities began, and at some point between teaching activities, up to $15 \mathrm{~min}$ after delivering the instruction, a social conflict was contrived or captured with people in the natural environment. For example, when the participant and his brother both wanted to go first at a game, data were collected on how the participant responded to the problem-solving steps outlined on the TA. If the participant engaged in any negative emotional responding, such as whining or crying during the presentation of the social conflict, a second conflict was not presented again that day.

Social conflicts to be used were determined by interviewing the participants and their parents and asking them what situations usually led to arguments with others. In addition, we observed naturally occurring social interactions between the participants and others and identified situations in which a social conflict arose and the participant failed to resolve the conflict. We then set up these scenarios to occur during the research session. For example, Russell stated he argued with his brother when his brother wanted to play a video game that he was already playing. So, we arranged for Russell's brother to request playing a video game that Russell was actively playing during the research session. Other times, the scenarios were genuinely captured, so we ran the research session upon capturing the naturally occurring conflict. For example, we observed that Patrick walked into his room to find that his brother had left dirty dishes on his desk and was notably upset as evidenced by his tone of voice, prosody, heavy breathing, and crying. The social conflicts contrived or captured are provided in Table 2.

\section{Baseline}

During baseline, in addition to the general procedures, problems occurred with at least two different people (e.g., parent, sibling; see Table 3 ). We did not provide any prompting or feedback in order to assess the extent to which participants resolved social conflicts independently. If the participant was not progressing through the conflict after $1 \mathrm{~min}$ of the conflict occurring, the conflict was ended by the interventionist resolving the problem. It was planned that if any distressed behavior (e.g., crying, screaming, negative statements, SIB, aggression) was observed for a duration of at least $10 \mathrm{~s}$, the conflict was to be ended by the interventionist resolving the problem; however, distressed behavior never occurred during baseline. Participants qualified to continue to the training phase if they scored $60 \%$ or less on the problem-solving TA. Two participants were excluded for not meeting this criterion.

\section{Pretraining Phase}

In this phase, the participant was taught how to use the problem-solving worksheet. In particular, the purpose of this phase was to evaluate whether simply providing the worksheet would result in improved problem-solving performance, that is, to ensure that the repertoires were not already present but just not under the stimulus control of the worksheet. The interventionist began by providing the participant with the following instruction: "This is a worksheet you can use to help you solve problems you have with other people. To use it, you will read each of the questions on it and answer them while the problem is happening to help you solve it." Then, the interventionist walked the participant through each question on the worksheet by pointing to each step and instructing the participant on what they should do for each worksheet question. For example, the interventionist pointed to the first question on the worksheet and said, "In this box you will ask yourself, 'What is the problem?' and you will write down or say out loud the problem that is happening between you and another person. After this, the interventionist pointed to the second question on the worksheet and said, "In this box you will ask yourself, "What do I think happened?' and you will write down what happened from your perspective." After going through each question on the worksheet with the participant in a similar 
Fig. 1 Problem-solving worksheet
Problem-Solving Worksheet

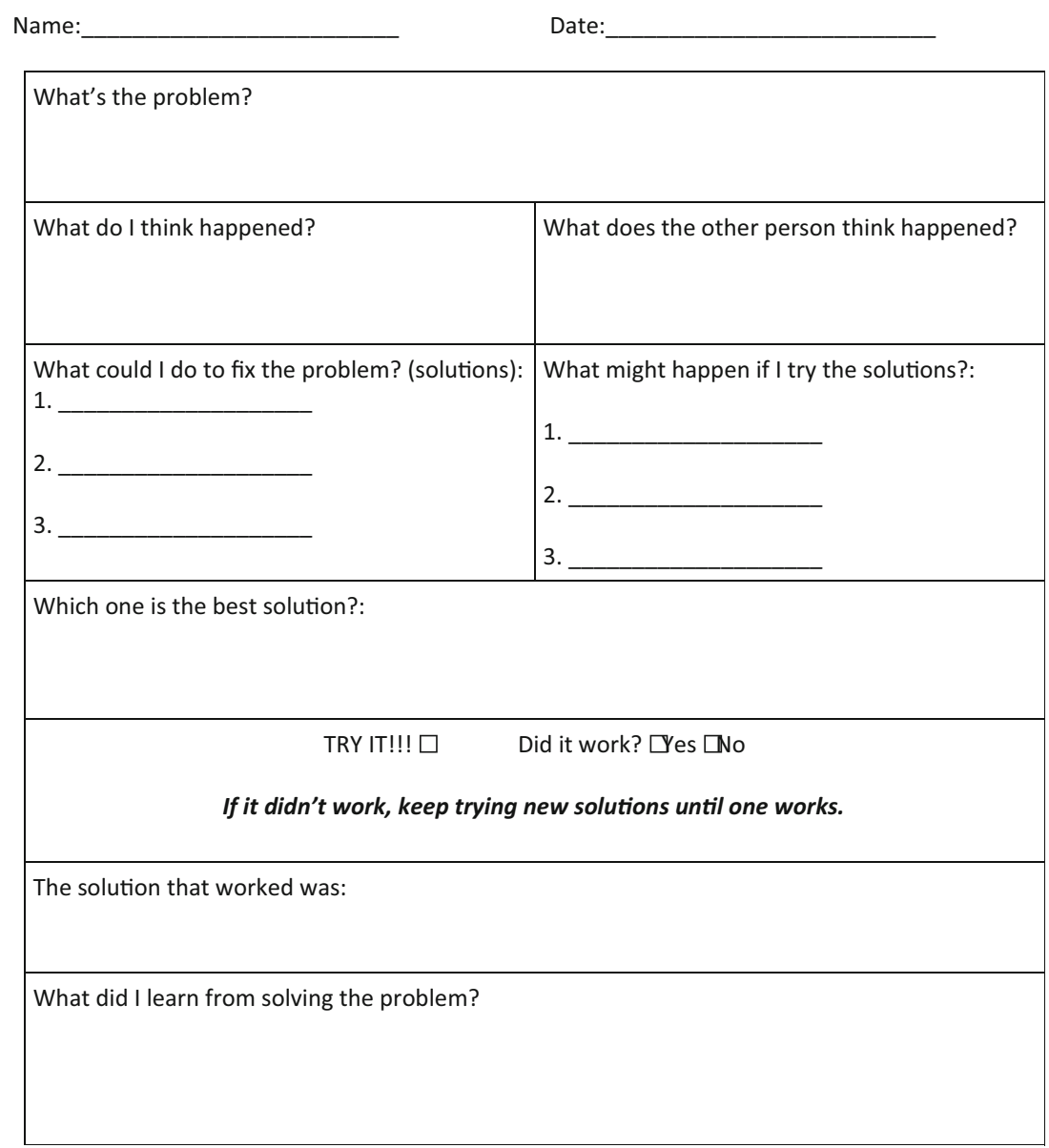

fashion, the interventionist presented the following instruction: "At some point today I am going to have a social problem with you; when it happens, you can use the worksheet to help you solve it." The participant was handed the blank worksheet alongside a pen/pencil. Participants were also told that they could call out their responses aloud if they did not want to write on the worksheet. At some point later in the session (between 5-15 min after reviewing how to use the worksheet), a social conflict was contrived between the interventionist and the participant. If the participant asked for help, they were told to do their best. Similar to baseline, no prompting, feedback, praise, or reinforcement was delivered. In addition, if any distressed behavior was observed for a duration of at least $10 \mathrm{~s}$, the problem was ended by the interventionist resolving the social conflict. If the participant was not progressing through solving the problem after $1 \mathrm{~min}$ of the conflict occurring, the conflict was likewise ended by the interventionist resolving it. Participants qualified to continue to the training phase if they scored $60 \%$ or less on the problem-solving TA in pretraining. No participants were excluded from continued participation during this phase.

\section{Training Phase}

In addition to the general procedures, during training, the participant was taught to engage in precurrent behavior (i.e., use the worksheet) to resolve social conflicts using multiple exemplar training, error correction, and reinforcement. At the beginning of each session, an informal preference assessment was conducted by asking participants what they would like to earn after resolving a conflict. Then, the participant was told that they would be able to access the predetermined reinforcer for more or less time depending on how many questions of the worksheet they completed correctly. The amount of time that was granted with the reinforcer was determined using a grading scale in which higher percentages of independent correct responding on the worksheet resulted in more time with the reinforcer (see Fig. 2). For example, if the participant scored $20 \%$ correct on the problem-solving worksheet, they received 2 min of access to their reinforcer (e.g., video game, free time), 
Table 2 List of social conflicts presented

Social Conflicts

\begin{tabular}{ll}
\hline Patrick & Oliver \\
\hline $\begin{array}{l}\text { (1) Patrick and his } \\
\text { brother both wanted } \\
\text { to use the Nintendo } \\
\text { Switch. }\end{array}$ & $\begin{array}{l}\text { an item from the } \\
\text { interventionist who } \\
\text { expressed being } \\
\text { bothered by him } \\
\text { taking it. }\end{array}$
\end{tabular}

(2) Brother borrowed Patrick's watch, and when Patrick asked for it back, his brother threw it at him.

(12) Mom was asking questions that she already knew the answer to because that information multiple times in the past.

(3) The interventionist said they could play a preferred scary game in $5 \mathrm{~min}$, but when 5 min elapsed, the interventionist said to do yoga. and Patrick made plans to walk to a river near their neighborhood, and on the day they had scheduled to go, the interventionist said she did not want to go after all.

(5) The interventionist did not want to watch any of the movies Patrick suggested. out on the table where Oliver was going to eat.

(14) Oliver was planning to go on an outing and the interventionist wanted to do work inside.

(15) While a group conversation was occurring, the interventionist ended the Oliver had given her

(4) The interventionist
(6) Brother left dirty dishes on Patrick's desk.
Russell

(21) Russell wanted to hang a blanket a certain way and wanted his brother to help him but brother did not want to help.

(22) Russell wanted to play a specific game whereas the interventionist wanted to play a different game.

(13) Brother left Legos (23) The conversation abruptly to "take a phone call." Oliver saw the phone's home screen and identified to the third person that the interventionist was lying.

(16) A group conversation was occurring, and Oliver was only addressing one of the members of the group and leaving out the other group member who expressed feeling left out.

(7) Patrick was making (17) The jokes using humor interventionists said
(25) The interventionist wanted to talk about cleaning her room and Russell wanted to talk about a new toy.

(26) The

interventionist and Russell made plans to go on a hike, and on the day they had scheduled to go, the interventionist said she could not go anymore.

(27) Brother wanted to use the computer
Table 2 (continued)

Social Conflicts

\begin{tabular}{|c|c|c|}
\hline Patrick & Oliver & Russell \\
\hline $\begin{array}{l}\text { that the } \\
\text { interventionist } \\
\text { indicated being } \\
\text { upset about. }\end{array}$ & $\begin{array}{l}\text { they would be back } \\
\text { in } 5 \text { min and did not } \\
\text { return after } 5 \text { min } \\
\text { had elapsed. }\end{array}$ & $\begin{array}{l}\text { while Russell was } \\
\text { playing on the } \\
\text { computer. }\end{array}$ \\
\hline $\begin{array}{l}\text { (8) Brother wanted to } \\
\text { be in the same room } \\
\text { as Patrick whereas } \\
\text { Patrick did not want } \\
\text { him in the room. }\end{array}$ & $\begin{array}{l}\text { (18) Oliver wanted to } \\
\text { talk about a } \\
\text { homework } \\
\text { assignment and the } \\
\text { interventionist } \\
\text { wanted to talk about } \\
\text { one of his skill } \\
\text { acquisition lessons. }\end{array}$ & $\begin{array}{l}\text { (28) Russell wanted to } \\
\text { play outside, and the } \\
\text { interventionist } \\
\text { wanted to play } \\
\text { inside. }\end{array}$ \\
\hline $\begin{array}{l}\text { (9) The interventionist } \\
\text { walked out of the } \\
\text { room while Patrick } \\
\text { was in the middle of } \\
\text { talking to the } \\
\text { interventionist. }\end{array}$ & $\begin{array}{l}\text { (19) The } \\
\text { interventionist } \\
\text { insisted that he and } \\
\text { Oliver play a video } \\
\text { game after Oliver } \\
\text { had already } \\
\text { expressed that he } \\
\text { did not want to play. }\end{array}$ & $\begin{array}{l}\text { (29) Russell wanted to } \\
\text { learn about a } \\
\text { website and was } \\
\text { arguing with brother } \\
\text { over what the } \\
\text { internet said about } \\
\text { the website and } \\
\text { what his brother was } \\
\text { saying about the } \\
\text { website. }\end{array}$ \\
\hline $\begin{array}{l}\text { (10) Patrick wanted to } \\
\text { tell the } \\
\text { interventionist about } \\
\text { a new recipe and } \\
\text { brother was } \\
\text { interrupting. }\end{array}$ & $\begin{array}{l}\text { (20) Brother kept } \\
\text { talking to Oliver } \\
\text { although Oliver had } \\
\text { told him he was } \\
\text { busy working on } \\
\text { something. }\end{array}$ & $\begin{array}{l}\text { (30) It was brother's } \\
\text { turn to use the } \\
\text { computer, but } \\
\text { Russell was in the } \\
\text { middle of an } \\
\text { important play. }\end{array}$ \\
\hline
\end{tabular}

Note: Sample of contrived or captured social conflicts encountered by Patrick, Oliver, and Russell. and if they scored $90 \%$ correct they received $13 \mathrm{~min}$ of access. A social conflict was then contrived and each independently performed step of the TA was praised. Access to the predetermined reinforcer was granted for a prespecified amount of time depending on the participant's percentage of correct responding.

Incorrect responses resulted in re-presentation of the step followed by an immediate prompt using a least-to-most prompting hierarchy. The first prompt used was a gestural prompt, which consisted of the interventionist pointing to (in-person sessions) or highlighting with a cursor (telehealth sessions) the current step of the worksheet. If the gestural prompt did not result in a correct response, the step was represented with an immediate directive prompt. The directive prompt consisted of the interventionist saying, "Ask yourself [step-related question]" (e.g. "Ask yourself, 'What is the problem?"”; "Ask yourself, 'What do I think happened?") while pointing to the current step on the worksheet. If the directive prompt did not result in a correct response, the step was re-presented with an immediate leading-question prompt. Leading-question prompts were individualized for each 
Table 3 People and problems presented each phase

\begin{tabular}{|c|c|c|c|c|}
\hline & Baseline & Training & Posttraining/Generalization & Natural Environment Probes \\
\hline \multicolumn{5}{|l|}{ People } \\
\hline Patrick & $\begin{array}{l}\text { Interventionist } 1 \text {, } \\
\text { Brother }\end{array}$ & $\begin{array}{l}\text { Interventionist 2, } \\
\text { Brother }\end{array}$ & $\begin{array}{l}\text { Interventionist 1, } \\
\text { Interventionist 3, } \\
\text { Brother, Peer }\end{array}$ & $\begin{array}{l}\text { Interventionist } 1 \\
\text { Interventionist } 2\end{array}$ \\
\hline Oliver & $\begin{array}{l}\text { Mom, } \\
\text { Interventionist 3, } \\
\text { Interventionist 4, } \\
\text { Brother }\end{array}$ & $\begin{array}{l}\text { Interventionist 1, } \\
\text { Interventionist 2, } \\
\text { Interventionist } 4\end{array}$ & $\begin{array}{l}\text { Interventionist } 1 \text {, } \\
\text { Interventionist } 4 \text {, } \\
\text { Mom, Brother, Dad, } \\
\text { Interventionist } 5\end{array}$ & $\begin{array}{l}\text { Interventionist } 4, \\
\text { Interventionist } 1\end{array}$ \\
\hline Russell & $\begin{array}{l}\text { Mom, Dad, } \\
\text { Interventionist 1, } \\
\text { Brother, } \\
\text { Interventionist } 2\end{array}$ & $\begin{array}{l}\text { Interventionist 2, } \\
\text { Brother }\end{array}$ & $\begin{array}{l}\text { Dad, Interventionist } 1 \text {, Interventionist } 2 \text {, } \\
\text { Brother }\end{array}$ & $\begin{array}{l}\text { Interventionist 2, } \\
\text { Brother }\end{array}$ \\
\hline \multicolumn{5}{|c|}{ Problems } \\
\hline Patrick & $1,2,8$ & $3-6$ & $1,7,8$ & $9-10$ \\
\hline Oliver & $11-14$ & $15-17$ & $12-14,18$ & 19-20 \\
\hline Russell & $21-24$ & $24-27$ & $21-23$ & $28-30$ \\
\hline
\end{tabular}

Note: People and social conflicts used across baseline, training, and posttraining conditions and during natural environment probes. Social conflicts and people used to assess generalization are included alongside people and social conflicts in posttraining.

conflict and each step of the TA. For example, "What is going on right now?" was used as a leading question for the first step of the worksheet (i.e., identifying the problem). If the leading question prompt did not result in a correct response, a choice prompt was presented. Choice prompts were also individualized for each conflict and each step of the TA using the following script: "Is the problem [correct/irrelevant possibility], or is the problem [correct/irrelevant possibility]?" (e.g., "Is the problem that we both want to go first [the problem], or is the problem that you need a place to sit?" [irrelevant to the problem]). A coin flip was used to randomize the order of correct/irrelevant choices provided. Finally, the most intrusive prompt provided was a full vocal model of the correct answer (e.g., "The problem is that we both want to go first."). It was planned that if the participants came up with three nonviable solutions, the aforementioned prompting hierarchy would be used to prompt them to think of at least one solution that would work to solve the problem; however, all participants proposed at least one viable solution during training, so this was not needed. The criterion for ending the training phase was for the participant to respond with at least $80 \%$ accuracy for three consecutive sessions with the interventionist. After this, the posttraining phase was introduced.

\section{Posttraining Phase}

At the beginning of each posttraining session, a variation of the following instruction was presented, "Even if you can solve the problem by yourself without the worksheet, I need you to use the worksheet so that I know what you are thinking." If participants began to resolve the conflict without using the worksheet, the instruction was re-presented. Other than the presence of that instruction, this phase was identical to baseline conditions, in that no feedback or reinforcement was provided at any point. Exemplars from baseline were re-presented during this phase (Table 3) to evaluate whether participants resolved social conflicts that they were unsuccessful in resolving prior to receiving the problem-solving training package.
Fig. 2 Reinforcement grading scale
Reinforcement Grading Scale

\begin{tabular}{|c|l|l|}
\hline Grading Scale: & My Grade: & \\
1. $0-19 \%=1$ minute & & \\
2. $20-29 \%=2$ minutes & \\
3. $30-39 \%=3$ minutes & \\
4. $40-49 \%=4$ minutes & \\
5. $50-59 \%=7$ minutes & & \\
6. $60-69 \%=8$ minutes & & \\
7. $70-79 \%=9$ minutes & & \\
8. $80-89 \%=11$ minutes & & \\
9. $90-99 \%=13$ minutes & & \\
10. $100 \%=15$ minutes & & \\
\end{tabular}




\section{Natural Environment Probes}

Natural environment probes were used to evaluate problem solving in the absence of the worksheet. The first natural environment probe was conducted during baseline to evaluate participants' problem-solving skills in the absence of the worksheet. During training, natural environment probes were contrived after participants scored at or above $80 \%$ correct on the problem-solving worksheet, with the exception of Oliver, who had a natural environment probe captured after the sixth training session. During posttraining, natural environment probes were graphed whenever captured. For example, if a naturally occurring social conflict arose at any time, it was captured as a natural environment probe. In addition, three consecutive natural environments probes were presented after completing posttraining sessions for all participants.

Follow-up natural environment probes were conducted at 2 (Patrick, Russell, and Oliver), 4 (Patrick and Russell), 6 (Patrick and Russell), and 10 (Patrick only) weeks posttraining to evaluate maintenance.

\section{Social Validity}

A social validity questionnaire (Table 4) was administered to each participant upon the completion of training. Participants were instructed to complete the questionnaire to the best of their ability and no additional feedback on their responses was provided. The questionnaire consisted of six questions (two each for goals, procedures, and outcomes; see Table 4) scored on a 5-point Likert scale: (1) strongly disagree, (2) disagree, (3) neutral, (4) agree, and (5) strongly agree. There were also two open-ended questions that asked participants to identify what they liked the most and least about the problem-solving training package.

\section{Results}

Figure 3 contains the results for Patrick (top panel), Oliver (middle panel), and Russell (bottom panel); these are described below, respectively. Patrick responded during baseline with $0 \%-8 \%$ accuracy in the presence of the worksheet and did not resolve the social conflict presented during the natural environment probe. During pretraining, Patrick performed with $0 \%$ accuracy in the presence of the worksheet. During training in the presence of novel problems, there was an immediate increase in correct responding, and he met the mastery criterion on the sixth training session. After training, during a natural environment probe (no worksheet), Patrick successfully resolved a contrived social conflict. During posttraining when untrained social conflict exemplars from baseline were repeated, Patrick consistently scored $100 \%$ using the problem-solving worksheet and also successfully resolved social conflicts during the natural environment probes (no worksheet). Maintenance was measured 2, 4, 6, and 10 weeks following training, and Patrick successfully resolved novel, naturally occurring social conflicts in the absence of a worksheet.

Oliver responded with $0 \%-21 \%$ accuracy during baseline in the presence of the worksheet and did not resolve the social conflict presented during the natural environment probe. During pretraining, Oliver scored 7\% correct in the presence of the worksheet. During training in the presence of novel problems, there was an immediate increase in correct responding, and he met the mastery criterion on the ninth training sessions. During session 15, we captured a naturally occurring social conflict, and Oliver successfully resolved it in the absence of the worksheet. During posttraining when untrained social conflict exemplars from baseline were repeated, Oliver scored 92\%-100\% correct and successfully resolved a social conflict during session 20 during a captured natural environment probe. After session 21, a 2-month period
Table 4 Social validity questionnaire items
Social Validity Questionnaire Items

1 I believe learning to solve social problems is important.

2 I think I will be more successful in my relationships with my family and friends if I am able to solve social problems.

3 I believe that the procedures we used to learn about solving social problems were acceptable.

4 I would recommend the social problem-solving lesson to others who want to work on their social problem-solving skills.

5 I believe that I am better at solving social problems after participating in the social problem-solving lesson.

6 I think that completing the social problem-solving lesson helped me solve social problems I have with my family/friends.

7 Please tell us what you liked the most about the social problem-solving lesson.

8 Please tell us what you liked the least about the social problem-solving lesson. 
Fig. 3 Percentage of correct problem-solving steps emitted by participants
Percentage of Correct Problem-Solving Steps Emitted by Participants

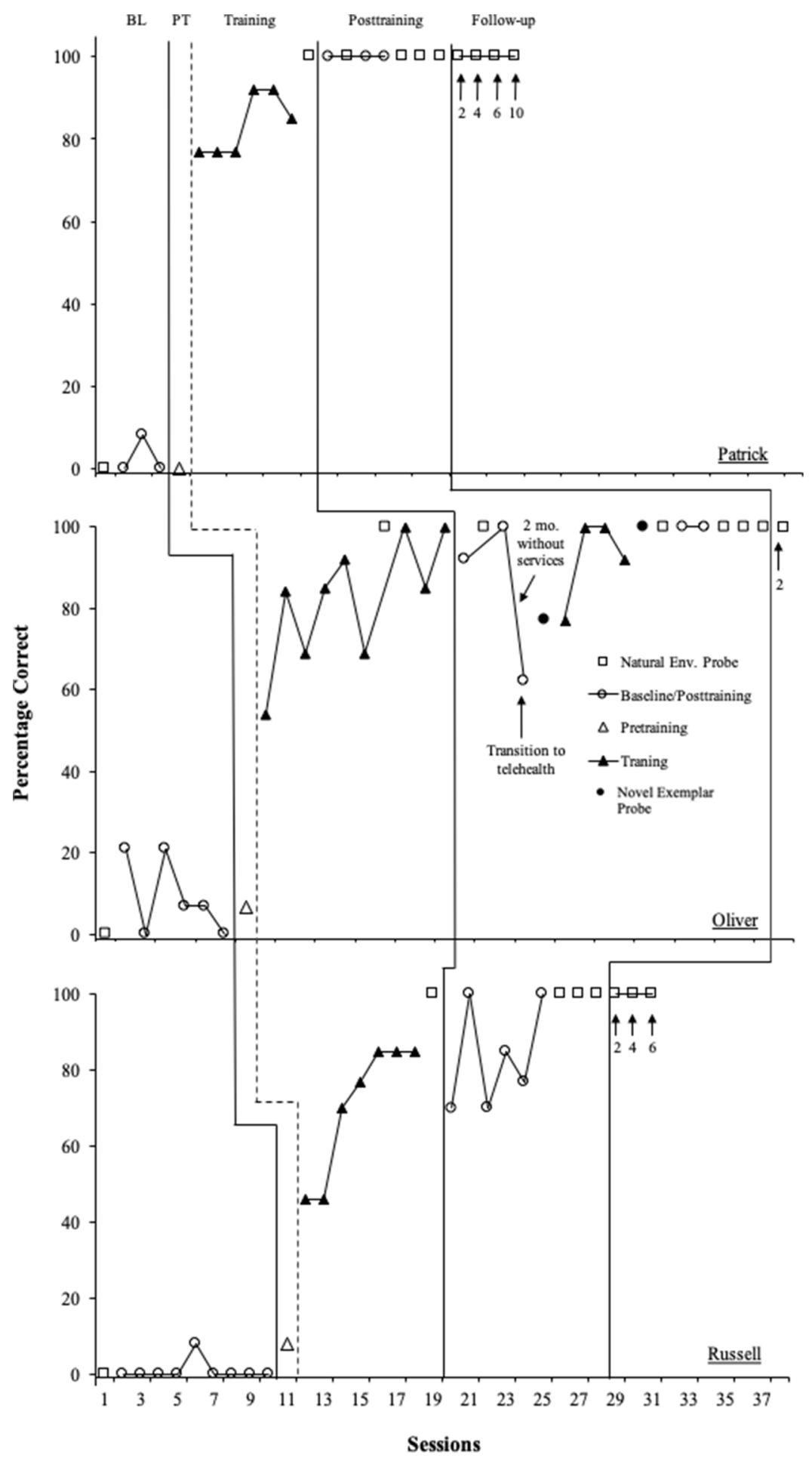

elapsed wherein Oliver did not receive services as a result of the COVID-19 pandemic. Upon returning to sessions using telehealth technology, Oliver scored $62 \%$ correct on the problem-solving worksheet under posttraining conditions. Because Oliver's performance notably decreased, a novel exemplar probe under baseline conditions was conducted to determine if Oliver should receive a booster training session, and he scored $77 \%$ correct. The novel exemplar probe consisted of the presentation of a social conflict that had not been contrived at any other time in 
the study. Given that Oliver scored below $80 \%$ on the novel exemplar probe, Oliver was provided with booster training until he re-met the mastery criterion of $80 \%-$ $100 \%$ correct across three consecutive sessions. The booster training conditions were identical to the training conditions. Then, another novel exemplar probe under baseline conditions was presented, and Oliver scored $100 \%$ correct. After this, a natural environment probe was captured in which Oliver successfully resolved a conflict in the absence of the problem-solving worksheet. Oliver scored $100 \%$ correct in the following session when he was presented with an untrained exemplar from baseline under posttraining conditions. Then, three natural environment probes were conducted and Oliver successfully resolved social conflicts in the absence of the worksheet. Maintenance was measured 2 weeks following posttraining in which Oliver successfully resolved a novel, naturally occurring social conflict in the absence of a worksheet.

Russell responded with 0\%-8\% accuracy during baseline in the presence of the worksheet and did not resolve the social conflict presented during the natural environment probe. During pretraining, Russell scored $8 \%$ correct in the presence of the worksheet. During training in the presence of novel problems, there was an immediate increase in correct responding, and he met the mastery criterion on the seventh training session. Moreover, Russell successfully resolved a contrived social conflict in the absence of the worksheet. During posttraining when untrained social conflict exemplars from baseline were repeated, Russell scored $70 \%-100 \%$ correct using the problem-solving worksheet and successfully resolved social conflicts in the absence of the worksheet. Maintenance was measured 2, 4, and 6 weeks following posttraining, and Russell successfully resolved novel, naturally occurring social conflicts in the absence of the worksheet.

\section{Social Validity}

Patrick and Russell scored the problem-solving training package as being highly acceptable with mean scores of 5 and 4.82 , respectively. Oliver's mean social validity score was 3.83. He scored "strongly agree" for one question and "agree" for three questions. The questions he scored as neutral included: (1) "I believe that I am better at solving social problems after participating in the social problem-solving lesson"; and (2) "I think that completing the social problem-solving lesson helped me solve social problems I have with my family/friends." Patrick identified what he liked most about the training package was that it was helpful to him, and Oliver identified what he liked most was feeling like he was right. The only reported dislike about the training package was that it was tedious (Oliver).

\section{Discussion}

The data from the current study suggest that multiple exemplar training, combined with a worksheet, was effective in teaching three individuals with ASD to resolve novel social conflicts occurring in the natural environment. In addition, generalization across untrained conflicts and people was observed from baseline to posttraining for all participants. These results are consistent with behavioral research conducted by Frampton and Shillingsburg (2018), Kisamore et al. (2011), Lora et al. (2019), Park and Gaylord-Ross (1989), and Sautter et al. (2011) in demonstrating that problem-solving strategies can be taught using behavioral strategies.

A noteworthy finding was that pretraining was insufficient to occasion the use of the worksheet during social conflicts. This finding is consistent with the behavioral skills training (BST) literature, which has shown instructions alone are generally ineffective compared to behavioral packages, such as BST (e.g., Feldman et al., 1989; Hudson, 1982; Ward-Horner \& Sturmey, 2012). This finding is also consistent with previous problem-solving research that found modeling and prompting resulted in superior responding as compared to other strategies, such as teaching rules (Kisamore et al., 2011).

The results of this study are also consistent with previous research conducted by Bernard-Optiz et al. (2001) in demonstrating an increase in the use of novel solutions by individuals with ASD. In particular, the results showed that precurrent behaviors were successful in bringing a variety of solutions (not just one type of solution) under the control of the conflict context. For example, types of solutions used by participants included many different repertoires, some of which have not been addressed in previous research such as apologizing, providing information, advocating for individual needs/wants, compromising, and removing oneself from the situation, along with others that have been targeted in previous research, such as requesting information (e.g., Shillingsburg et al., 2011), requesting tangibles (e.g., Bourret et al., 2004), and requesting help/removal (e.g., Rodriguez et al., 2017; see Table 5). A potential limitation of this study is that we did not preplan the types of solutions we would teach, so exposure to types of solutions was not controlled for or counterbalanced. Therefore, it is possible that variation in the types of solutions used affected the results. However, consistent results were obtained across the three participants, so there is no direct evidence that inconsistency affected the results. In addition, training a variety of strategies, all of which have the same function, to solve the problem, may be considered a form of multiple exemplar training in itself, and therefore may have contributed to the favorable generalization that was observed. Still, uncontrolled variables are often frowned upon in research, so future researchers may want to consider controlling the number of each type of solution taught to participants. 
Table 5 Solutions used by participants

\begin{tabular}{llll}
\hline Solutions & Patrick & Oliver & Russell \\
\hline & $\mathrm{n}(\%)$ & & \\
Apologize & $2(9)$ & $2(5)$ & $1(3)$ \\
Provide information & $3(14)$ & $8(24)$ & $1(3)$ \\
Request information & $6(27)$ & $8(24)$ & $5(17)$ \\
Advocate for wants/needs & $3(14)$ & $9(27)$ & $4(13)$ \\
Compromise & $4(18)$ & $4(12)$ & $13(43)$ \\
Remove self from situation & $1(4)$ & $1(2)$ & $0(0)$ \\
Request tangible & $0(0)$ & $1(2)$ & $0(0)$ \\
Request help/ removal & $4(18)$ & $1(2)$ & $5(17)$ \\
\hline
\end{tabular}

Note: Number and percentage of types of solutions used across social conflicts by Patrick, Oliver, and Russell

This study expanded upon past research by capturing and contriving social conflicts within each participants' natural environment. By conducting training with naturally occurring stimuli and "training loosely" (Stokes \& Baer, 1977), generalization was promoted to ensure that participants acquired a repertoire for resolving social conflicts, rather than generating solutions only for specifically targeted conflicts. A compelling finding was that participants successfully resolved social conflicts in the absence of the worksheet during natural environment probes. Thus, the current study contributes to the literature by demonstrating that problem-solving strategies (i.e., worksheet use) can result in participants with ASD demonstrating successful generalization to untrained social conflicts occurring in the natural environment in the absence of a worksheet. The worksheet may be conceptualized as a prompt, that may have facilitated acquisition at first and was then no longer necessary to occasion the problem-solving chain of behaviors. Future research could consider teaching social conflict resolution in the absence of a worksheet, possibly by teaching each step of the problem-solving worksheet. Future research could also evaluate whether teaching a shorter problem-solving chain would be efficacious. For example, the last two steps of the worksheet could be omitted.

Continued successful problem-solving during natural environment probes also has implications for the possibility that some of the mediating behaviors previously cued by the worksheet were completed by participants on a covert level when the worksheet was no longer present. However, it is not possible to identify with any certainty whether participants were engaging in covert behavior. Given that participants were unsuccessful with resolving social conflicts during baseline, but were successful with resolving naturally occurring social conflicts after being trained to follow the problemsolving steps, and continued to resolve social conflicts effectively during posttraining, it seems possible that participants completed some of the steps on a covert level. In addition, after completing training, anecdotal observations found that participants engaged in overt behavior that suggested the possibility that they were engaging in covert completion of the steps, such as overtly saying, "You might think I am just not wanting to share the computer, but really I have been doing schoolwork all morning and just started my turn" (Step 3: What does the other person think happened?). It is also possible that participants engaged in visual imagining of the worksheet during natural environment probes. Skinner (1969) described precurrent behaviors of visual imagining in mathematical problem-solving and Kisamore et al. (2011) attempted to directly train visual imagining problem-solving behavior, so it is possible that the participants in this study engaged in covert imagining behavior. As with any covert behavior, it is not possible for researchers to directly measure it, but future research could attempt to train participants to observe and record their own covert verbal behavior, in order to provide an approximate measurement of the generalization of problem-solving repertoires to the covert level. For example, researchers might ask the participant, "How did you figure out how to solve that problem?," to which a participant might respond with something like, "I imagined the worksheet in my head until I thought of the solution." To the extent that participants are not directly trained to give specific verbal reports of this kind, such verbal reports might provide interesting supplementary data on the possibility of covert problem solving behavior.

It is interesting that all participants were observed to attempt to solve problems without using the worksheet in posttraining, although they were presented with the worksheet. In these instances, participants were reminded to use the worksheet. This indicated that participants had acquired problem-solving skills and no longer needed the worksheet; however, it was necessary to have participants use the worksheet in order to compare their posttraining performance to their baseline performance (because we could not measure their covert behavior to identify if they were implementing the problem-solving steps). Future research should evaluate methods to measure problem-solving skills in ways that allow participants to demonstrate their newly acquired skills without being limited by the apparatus/ materials of the experiment. A possible solution could be to consider problem resolution as the primary dependent variable and evaluate pre- and posttraining data for conflict resolution following training in a problem-solving strategy.

We also found that emotional responding occasionally occurred upon presentation of social conflicts and possibly interfered with participants' performance with resolving social conflicts. For example, Patrick was occasionally observed crying in response to a social conflict, which was followed by engaging in additional emotional self-regulation behaviors (e.g., take deep breaths, drink some water) and then successfully resolving the conflict. However, given that participants 
were successful in resolving social conflicts albeit experiencing emotional responding, the likelihood that emotional responses hindered learning problem-solving skills is low. Data were not collected on emotional responding; however, the team anecdotally observed that emotional responding decreased as participants learned to use the problem-solving worksheet. Future research should consider measuring emotional responding when teaching individuals to resolve social conflicts and may also investigate the role of emotionregulation repertoires on problem-solving skills of individuals with ASD.

One potential limitation of the study is that we did not assess whether the trained problem-solving repertoires specifically came under the stimulus control of problems. Put another way, although the training procedure trained participants to identify problems and to discriminate which social situations were problems, we did not formally collect data on whether such discrimination was occurring. Although formal data were not collected on unnecessary or inappropriate application of problem-solving skills, the research team anecdotally reported that they never observed this to occur.

Another limitation of the study is that procedural fidelity data were not collected, so the degree to which procedures were implemented with fidelity is unknown. In addition, social validity information was not collected from family members. Given that social conflicts often occurred between the participants and their family members, future research could assess the family members' impressions of the intervention by collecting social validity information from family members with whom conflicts typically occurred

Probably the most notable limitation of the study was that all solutions effectively resolved the current social conflict, because we primed the people who had social conflicts with the participants to make sure the participants' solutions were successful. This was done by vocally instructing individuals present within the session that if a social conflict arose between them and the participant, they should allow whatever solution is presented by the participant to resolve the social conflict. In other words, whatever solution the participant proposed received functional reinforcement by the conflict being resolved. This was done to ensure the problem-solving sequence resulted in reinforcement; however, the schedule of reinforcement for problem solving in the natural environment is certainly not fixed. Future research should make a transition to a variable schedule of reinforcement when teaching problem-solving skills. In addition, when a strategy to resolve a conflict fails, one must engage in a subsequent behavior chain of problem solving. Therefore, future research should investigate the additional problem-solving steps required when an initial solution is unsuccessful.

Overall, the current study was successful in teaching three individuals with ASD to resolve social conflicts occurring in their every-day lives using a problem-solving worksheet, multiple exemplar training, error correction, rules, and reinforcement. In addition, the results of this study indicate that acquired skills for problem resolution successfully generalized to untrained social conflicts and maintained after training. The most notable aspect of the study was that the findings of this study indicate that overt precurrent behaviors, such as completing a worksheet, were not needed by participants to successfully resolve social conflicts after receiving training in engaging in such precurrent behaviors. As noted by Frampton and Shillingsburg (2018), it is important to identify efficacious methods for teaching complex skills, such as resolving social conflicts, that often occur at the covert level. Finally, it should be noted that according to traditional psychology, problem solving is associated with executive function (EF; Zelazo et al., 1997). In our clinical practice, skills associated with EF have become a requested repertoire to be targeted during behavioral intervention. For example, individualized educational planning (IEP) team members and parents have requested goals related to EF skills. The findings of this study demonstrate that behavioral procedures can be used to address a skill that is traditionally categorized as being an EF skill.

Acknowledgments Victoria D. Suarez is Latina, Adel C. Najdowski is bi-racial: Latina and White, Jonathan Tarbox is White, Emma I. Moon is White, Megan St. Clair is White, and Peter Farag is Egyptian. We thank Jasmyn Pacheco, Lauri Simchoni, and Bryan Acuña for their assistance with this project.

\section{Declarations}

Conflict of Interest The authors declare that they have no conflict of interest.

Informed Consent Informed consent was obtained by all human participants using a consent form approved by Endicott College's IRB.

\section{References}

Agran, M., Blanchard, C., Wehmeyer, M., \& Hughes, C. (2002). Increasing the problem-solving skills of students with developmental disabilities participating in general education. Remedial \& Special Education, 23(5), 279-288. https://doi.org/10.1177/ 07419325020230050301

American Psychiatric Association. (2013). Diagnostic and statistical manual of mental disorders (5th ed). Washington, DC.

Axe, J. B., Phelan, S. H., \& Irwin, C. L. (2019). Empirical evaluations of Skinner's analysis of problem solving. Analysis of Verbal Behavior, 35(1), 39-56. https://doi.org/10.1007/s40616-018-0103-4

Bernard-Optiz, V., Sriram, N., \& Nakhoda-Sapuan, S. (2001). Enhancing social problem solving in children with autism and normal children through computer-assisted instruction. Journal of Autism \& Developmental Disorders, 31(4), 377-384. https://doi.org/10. 1023/A:1010660502130 
Best, J. R., Miller, P. H., \& Jones, L. L. (2009). Executive functions after age 5: Changes and correlates. Developmental Review, 29(3), 180 200. https://doi.org/10.1016/j.dr.2009.05.002

Bonete, S., Calero, M. D., \& Fernández-Parra, A. (2015). Group training in interpersonal problem-solving skills for workplace adaptation of adolescents and adults with Asperger syndrome: A preliminary study. Autism, 19(4), 409-420.

Bourret, J., Vollmer, T. R., \& Rapp, J. T. (2004). Evaluation of a vocal mand assessment and vocal mand training procedures. Journal of Applied Behavior Analysis, 37(2), 129-144. https://doi.org/10.1901/ jeab.2010.93-455

Feldman, M. A., Case, L., Rincover, A., Towns, F., \& Betel, J. (1989). Parent education project III: Increasing affection and responsivity in developmentally handicapped mothers: Component analysis, generalization, and effects on child language. Journal of Applied Behavior Analysis, 22(2), 211-222. https://doi.org/10.1901/jaba.1989.22-211

Frampton, S. E., \& Shillingsburg, M. A. (2018). Teaching children with autism to explain how: A case for problem solving? Journal of Applied Behavior Analysis, 51(2), 236-254. https://doi.org/10. 1002/jaba.445

Garon, N., Bryson, S. E., \& Smith, I. M. (2008). Executive function in preschoolers: A review using an integrative framework. Psychological Bulletin, 134(1), 31-60. https://doi.org/10.1037/ 0033-2909.134.1.31

Hudson, A. M. (1982). Training parents of developmentally handicapped children: A component analysis. Behavior Therapy, 13(3), 325-333. https://doi.org/10.1016/S0005-7894(82)80041-5

Kisamore, A. N., Carr, J. E., \& LeBlanc, L. A. (2011). Teaching preschool children to use visual imagining as a problem-solving strategy for complex categorization tasks. Journal of Applied Behavior Analysis, 44(2), 255-278. https://doi.org/10.1901/jaba.2011.44-255

Lora, C. C., Kisamore, A. N., Reeve, K. F., \& Townsend, D. B. (2019). Effects of a problem-solving strategy on the independent completion of vocational tasks by adolescents with autism spectrum disorder. Journal of Applied Behavior Analysis, 53(1), 175-187. https://doi. org/10.1002/jaba.558

Luciano, C., Gil-Luciano, B., Barbero, A., \& Molina-Cobos, F. (2020). Perspective-taking, empathy, and compassion. In M. Fryling, R. Rehfeldt, J. Tarbox, \& L. Hayes (Eds.), Applied behavior analysis of language and cognition: Core concepts and principles for practitioners. Context Press.

Palmer, D. C. (1991). A behavioral interpretation of memory. In L. J. Hayes \& P. N. Chase (Eds.), Dialogues on verbal behavior (pp. 261-279). Context Press.
Palmer, D. C. (2009). Response strength and the concept of the repertoire. European Journal of Behavior Analysis, 10(1), 49-60. https://doi. org/10.1080/15021149.2009.11434308

Park, H. S., \& Gaylord-Ross, R. (1989). A problem-solving approach to social skills training in employment settings with mentally retarded youth. Journal of Applied Behavior Analysis, 22(4), 373-380.

Rodriguez, N. M., Levesque, M. A., Cohrs, V. L., \& Niemeier, J. J. (2017). Teaching children with autism to request help with difficult tasks. Journal of Applied Behavior Analysis, 50(4), 717-732. https://doi.org/10.1002/jaba.420

Sautter, R. A., LeBlanc, L. A., Jay, A. A., Goldsmith, T. R., \& Carr, J. E. (2011). The role of problem solving in complex intraverbal repertoires. Journal of Applied Behavior Analysis, 44(2), 227-244. https://doi.org/10.1901/jaba.2011.44-227

Shillingsburg, M. A., Valentino, A. L., Bowen, C. N., Bradley, D., \& Zavatkay, D. (2011). Teaching children with autism to request information. Research in Autism Spectrum Disorders, 5(1), 670-679. https://doi.org/10.1016/j.rasd.2010.08.004

Skinner, B. F. (1953). Science and human behavior. Free Press.

Skinner, B. F. (1969). Contingencies of reinforcement: A theoretical analysis. Prentice-Hall.

Skinner, B. F. (1984). An operant analysis of problem solving. Behavioral \& Brain Sciences, 7, 583-613. https://doi.org/10.1017/ S0140525X0002741

Stokes, T. F., \& Baer, D. M. (1977). An implicit technology of generalization 1. Journal of Applied Behavior Analysis, 10(2), 349-367. https://doi.org/10.1901/jaba.1977.10-349

Szabo, T. (2020). Problem solving. In M. Fryling, R. Rehfeldt, J. Tarbox, \& L. Hayes (Eds.), Applied behavior analysis of language and cognition: Core concepts and principles for practitioners. Context Press.

Ward-Horner, J., \& Sturmey, P. (2012). Component analysis of behavior skills training in functional analysis. Behavioral Interventions, 27(2), 75-92. https://doi.org/10.1002/bin.1339

Zelazo, P. D., Carter, A., Reznick, J. S., \& Frye, D. (1997). Early development of executive function: A problem-solving framework. Review of General Psychology, 1(2), 198-226. https://doi.org/10. 1037/1089-2680.1.2.198

Publisher's Note Springer Nature remains neutral with regard to jurisdictional claims in published maps and institutional affiliations. 